R OCZNIKI HUMANIST Y C Z N E

Tom LXIX, zeszyt 5 - 2021

ZESZYT SPECJALNY / SPECIALE UITGAVE

DOI: http://doi.org/10.18290/rh21695sp-8

JELENA NESIĆ

\title{
HET IDEE VAN VERZOENING TUSSEN BLANK EN ZWART IN KOEN PEETERS' DE MENSENGENEZER*
}

\begin{abstract}
A bstract. De Congo-roman is een belangrijk subgenre in de Vlaamse literatuur. Al sinds de zestiende eeuw werd er in de Nederlandstalige teksten over Afrika geschreven. De interesse voor dit continent bleef in de volgende eeuwen stijgen. In dit artikel zal de thematiek van de recent gepubliceerde Congo-roman De mensengenezer (2017) van de contemporaine Vlaamse auteur Koen Peeters (geb. 1959) worden besproken. De focus in deze bijdrage ligt op de verhouding tussen de blanken en de zwarten, in het kader van de Congo-roman. De meeste Congo-romans van de twintigste eeuw en eerder toonden het beeld dat de zwarten inferieur aan de blanken zijn. In plaats daarvan wordt er in De mensengenezer het idee van verzoening tussen deze twee groepen gepresenteerd.
\end{abstract}

Trefwoorden: Congo-roman; Koen Peeters; relaties; kolonialisme; postkolonialisme.

\section{INLEIDING}

Het ontstaan van de Congo-roman is onvermijdelijk met het koloniale tijdperk verbonden. Batavia (1858) van Hendrik Conscience (1812-1883) wordt als de "eerste Vlaamse koloniale roman" beschouwd (Renders, Koloniseren 59-60). In deze roman wordt Congo, het land, allegorisch als Congo, de zwarte slaaf van hopman Van den Broeck afgebeeld (Renders, Koloniseren 65-67). Congo wordt een belangrijk thema in de twintigste eeuw, vooral sinds de dekolonisatie van dit land in de jaren zestig, en blijft relevant tot vandaag de dag. ${ }^{1}$ De dekolonisatie van Afrika in de jaren zestig betekende de tijd van

JELENA NesiĆ, MA - Universiteit van Belgrado; e-mail: jelena.nesic@protonmail.ch; ORCID: https://orcid.org/ 0000-0002-8131-9165.

* Dit artikel is gebaseerd op mijn onuitgegeven masterscriptie Een postkoloniaal kader van de kwestie van trauma en schuld in de roman De mensengenezer, die in 2019 verdedigd is aan de Universiteit van Belgrado.

${ }^{1}$ Zie, bijvoorbeeld, discussies rondom het in 2018 gerenoveerde Koninklijk Museum voor Midden-Afrika in Tervuren, de docureeks Kinderen van de kolonie uit 2018-2019 of het rapport uit 2019 van de VN-werkgroep over racisme in België. 
zelfonderzoek; meerdere naties van het continent streefden ernaar om eigen instituties op te bouwen (Buelens 457-461). Niettemin zouden zich twee grote machten van de Koude Oorlog, de Verenigde Staten en de Sovjet-Unie, mengen in en invloed hebben op het verdere verloop van de Afrikaanse geschiedenis (Buelens 472-477). Na het negentiende-eeuwse kolonialisme is er vandaag de dag vaak ook sprake van neokolonialisme, zowel in Afrika als in andere landen ter wereld.

De auteur van De mensengenezer is Koen Peeters, een hedendaagse Vlaamse schrijver. Zijn eerste roman, Conversaties met $K$., is in het jaar 1988 gepubliceerd (Brems 575). Peeters schreef nadien meer romans en verhalen, en ook een dichtbundel. Voor de meeste van zijn werken ontving hij prijzen, zoals voor De mensengenezer. Deze roman is in 2017 gepubliceerd en is met de ECI Literatuurprijs 2017, ECI Lezersprijs 2017, en de Confituur Boekhandelsprijs 2018 bekroond (Peters, "Koen Peeters wint"). In De mensengenezer gaat Peeters door met het onderzoeken van Afrika dat hij in Duizend heuvels (2012) begonnen was. Matthieu Sergier (283-292) bespreekt het heterolinguïsme van het taalgebruik in Peeters' Duizend heuvels en De mensengenezer.

In deze bijdrage wordt onderzocht hoe het idee van verzoening tussen blank en zwart zich manifesteert in Peeters' De mensengenezer. Bij het idee van verzoening wordt vooral de verhouding van de blanken tegenover de zwarten ten opzichte van het (post)koloniale verleden bedoeld. Bij de analyse van dit aspect van De mensengenezer wordt er gebruik gemaakt van theoretische postulaten van Edward W. Said (1935-2003) over "de Ander/het Anderszijn" ("the Other/Otherness"). Said bespreekt zijn theorie van constructie van het Oosten door het Westen in zijn invloedrijke culturele studie Orientalism (1978). Said (1-2) stelt dat "de Oriënt [...] ook een van Europa's diepste en meest terugkerende beelden van de Ander is. Daarnaast heeft de Oriënt eraan bijgedragen om Europa (of het Westen) te definiëren als zijn contrasterende beeld, idee, persoonlijkheid, ervaring". De Oriënt wordt door de westerse Orientalisten beschouwd als "irrationeel, verdorven (gevallen), kinderlijk, "anders", in tegenstelling tot de "rationele, deugdzame, volwassen, 'normale' Europeaan" (Said 40).

\section{HET BEELD VAN DE ANDER}

De mensengenezer is een fictieve roman gebaseerd op echte personen en hun verhalen en gebeurtenissen. Er zijn twee vertellers in de roman, met uit- 
zondering van het laatste hoofdstuk, waarin de auteur zelf aan het woord is. De eerste verteller is Remi, een gepensioneerde professor antropologie die nu als psychiater werkt. Hij vertelt over zijn leven in de Westhoek, hoe hij tot de jezuïetenorde toetrad, en hoe hij naar Congo ging en terugkeerde. De vertelde tijd omvat in deze hoofdstukken de periode van de jaren vijftig tot het einde van de jaren zestig van de twintigste eeuw. Remi bevindt zich in Congo vlak na zijn onafhankelijkheid. De tweede verteller is Remi's voormalige student, eigenlijk het andere "ik" van Koen Peeters, die het leven van zijn professor in het heden, dus in de eenentwintigste eeuw, zorgvuldig onderzoekt.

Toen Remi klein was, luisterde hij naar de verhalen van zijn oom Marcel over de "geest van de Westhoek" en de mysterieuze zwarte soldaat Pius ("de vrome" in het Latijn), die gesneuveld was in de Eerste Wereldoorlog. ${ }^{2}$ Zijn oom vertelt hem meer over het geheime woord dat de zwarte soldaat tijdens de oorlog als bezweringsformule gebruikte. Dat is het woord "carabouya". Later blijkt dat dit woord geen Congolees woord is; maar de naam van een Brussels snoepje. De Congolezen die dit snoepje verkochten, riepen volgens het verhaal: "Carabouya, carabouya. Alleman moet leven. Wit en zwart. Carabouya" (Peeters, De mensengenezer 255). Deze zin dient als een soort motto van de roman. Pius is afgebeeld als een gelovige man die vaak bezweringsformules in zijn taal gebruikte en houten beeldjes maakte. Een zekere Richard uit Brussel zat met hem in hetzelfde regiment. Richard en de andere soldaten beschouwden Pius als hun "persoonlijke geluksbrenger" en hun zwarte soldaat (Peeters, De mensengenezer 87-88). Wat hen vooral opviel waren Pius houten beeldjes en zijn vreemde woorden. Het kan lijken alsof het regiment Pius alleen als een soort talisman beschouwde. We zouden dus niet verwachten dat Richard en Marcel zich na de oorlog van Pius met ontroering herinneren. Oom Marcel zegt dat hij elke keer opnieuw aan Pius denkt wanneer hij zijn beitels gebruikt (Peeters, De mensengenezer 88). De toon van Richard en Maurice is niet belachend of kwaadaardig. Het wordt benadrukt dat Pius één van hen was - "onze Pius, onze zwarte soldaat" zegt Maurice (Peeters, De mensengenezer 253). Dit is een opmerkelijk motief dat ook later in het verhaal herhaald en omgedraaid zal worden wanneer Remi naar Yitaanda komt.

\footnotetext{
${ }^{2}$ Historica Griet Brosens onderzocht de kwestie van tweeëndertig Congolese soldaten die tijdens de Eerste Wereldoorlog aan de kant van België vochten (Brosens 253-265). Peeters vertelt aan het einde van De mensengenezer dat hij geïnspireerd was door het personage van François Mabilla, over wie Brosens schreef (Peeters, De mensengenezer 318-319).
} 
Aan het Instituut van Kimwenza in Congo ontmoet hij Frederic, een zwarte student, die het woord "jullie" tegenover hem gebruikt:

'Waarom mochten wij van jullie in Lovanium geen rechten studeren? Waren jullie bang dat wij te slim zouden worden? Slimmer dan jullie?'

Ik hoorde hem 'jullie' zeggen tegen mij. Voor mij was dat een schok. Wie was ik als ik bij die ene groep werd weggezet? (Peeters, De mensengenezer 185)

Zo een reactie van Frederic kan als het gevolg van het koloniale discours van de twee tegengestelde kanten van "ons" en "de ander" worden beschouwd. Dat Frederic het woord "jullie" tegenover Remi gebruikt terwijl hij zeker aan de blanke machthebbers van vroeger denkt is niet ongewoon, aangezien dat het verschil tussen blank en zwart door het koloniale systeem zwaar ondersteund was, waardoor het nog lang bleef bestaan in de levens van de gekoloniseerde mensen. $\mathrm{Nu}$ in de jaren zestig, na de onafhankelijkheid, voelt Frederic zich vrijer om zijn mening te uiten over deze verhouding. Hij roept het verschil tussen "ons" en "de ander" op zodat het door middel van gesprek hopelijk overbrugd kan worden. Het is nodig dat de beide kanten samen tot verzoening komen - voor zijn wat scherpe woorden excuseert hij zich, maar Remi zegt dat dat niet hoeft (Peeters, De mensengenezer 185). Als Remi met Taata Gabriel, een oude camioneur, praat gebruikt hij ook toevallig het woord "jullie" en excuseert zich: "Hebben jullie nog fetisjen?' vroeg ik na enige tijd. Ik voelde zelf dat mijn vraag te snel kwam, dat ik te ongeduldig was, en hoe ik nu zelf ook 'jullie' tegen hem had gezegd. 'Mag ik zoiets wel vragen?' vroeg ik, mij excuserend" (Peeters, De mensengenezer 259).

In het deel van de roman waar het verhaal in Congo plaatsvindt, zijn herinneringen aan het koloniale verleden aanwezig, zoals, bijvoorbeeld, de herinneringen van de zwarte priesters aan alle namen die voor hen in gebruik waren:

'Wie waren wij vroeger, eigenlijk?' vroeg een van hen, wat badinerend.

'Ja, soms vraag je je af wie wij vroeger zijn geweest,' zei de subminister. [...]

'Negers,' poneerde een van hen. 'Vroeger waren wij negers. Soms ook met een hoofdletter geschreven. Wij waren les Nègres.'

'Daarna waren wij les noirs,' haakte iemand snel in. 'Soms werd dat eveneens met hoofdletter geschreven, les Noirs.'

'Ik ken er zo nog,' zei een volgende fijntjes. 'Les Aborigènes de l'Afrique. Men noemde ons soms ook de verondersteld-primitieven.' [...]

'Wij waren les gens de couleur du Congo et du Ruandi-Urundi,' probeerde weer een ander. 
'Wij waren Bantoes,' zei iemand, en hij sprak dat uit als een blanke die de primitieve diklippige zwarte medemens imiteert. Ze proestten het uit. [...] (Peeters, De mensengenezer 218-219)

Deze herinnering van de zwarte priesters roept het koloniale verleden op in die zin dat het noemen en classificeren van wat onbekend was één van de strategieën van dominatie van de kolonisatoren was, zoals Said dat stelt (72, 221-222). De kolonisatoren gaven nieuwe namen aan onbekende begrippen omdat ze deze niet konden verstaan maar wel wilden veroveren. Een naam geven aan iets is een soort verovering; als het begrip een naam heeft is het niet meer onbekend. In het geval van de genoemden betekenden deze namen meestal niets. Het vraag van identiteit blijft bij de zwarte priesters wie waren zij? - omdat hun oude identiteiten zijn gewist en opnieuw geconstrueerd. In deze passage is de verwarring van alle namen merkbaar; er waren er meerdere, verschillende namen voor dezelfde mensen, maar uiteindelijk kunnen de zwarte priesters niet zeggen dat zelfs één van deze namen hen echt vertegenwoordigt. Opmerkelijk is het ook dat de subminister op Remi's vraag: "En wie waren wij Belgen dan, in deze gemeenschappelijke geschiedenis?", met een frase uit Commentarii de Bello Gallico (58-49 voor Christus) van Julius Caesar beantwoordt: "De tous les peuples de la Gaule, les Belges sont les plus braves" (Peeters, De mensengenezer 219). Het kan met geen zekerheid worden gezegd dat de "Belgae" waarover Caesar schreef de voorouders van de Belgen van vandaag zijn, dus de identiteitsvraag geldt op een bepaalde manier voor Remi ook.

Wanneer Remi naar de zwarte bisschop in Popokabaka gaat, zegt de bisschop tegen hem, met wat ironie: "Jij bent een blanke die zwarter wil zijn dan de zwarten. Over sommige zaken kunnen wij moeilijk met jullie praten" (Peeters, De mensengenezer 248). De bisschop is afgebeeld als wat wantrouwig maar niet vijandig tegenover Remi. In deze situatie, zoals bij Frederic, wordt het verschil tussen de ene en de andere groep onderstreept. Deze constructie duidt de gedachte aan dat er nog steeds hindernissen bestaan voor het wederzijds begrijpen, zoals in het geval bij Frederic. Remi probeert deze hindernissen te overbruggen door dieper in de taal en cultuur van de Yaka te gaan.

Uiteindelijk gaat Remi naar het dorp Yitaanda, waar de Yaka wonen. Onmiddellijk na zijn aankomst in het dorp wordt hij als een herboren voorouder van de dorpelingen, een "revenant", verwelkomd. Remi is enigszins verrast, en merkt op dat hij wit is, terwijl de inwoners donker van kleur zijn. 
Daarop zeggen de dorpelingen: "Natuurlijk, [...] maar onze voorouders in de aarde zijn ook wit. Wit als beenderen" (Peeters, De mensengenezer 266). Hierbij wordt het beeld van "de ander" tenslotte als het beeld van "ons(zelf)" erkend. Dezelfde krachten beïnvloeden de levens van ieder mens. Zoals Sergier (292) dat stelt: "[...] We zijn van meet af aan de dragers van een andersheid die we met de andere delen [...]." Voordat Remi definitief uit Yitaanda vertrekt, herinneren de dorpsbewoners hem er nog een keer aan dat hij één van hen is (Peeters, De mensengenezer 300). Op deze manier wordt Remi in Yitaanda zoals Pius in de Westhoek als "een andere die van ons is" afgebeeld. Remi verlaat Yitaanda, treedt uit bij de jezuïetenorde en gaat terug naar de Westhoek. Nadat hij in de Westhoek terug is, bezoekt Remi de graven van zijn moeder en oom, en zegt daar gebeden in de vorm van bezweringsformules in de taal van de Yaka. Na zijn eigen genezing is Remi bereid om anderen te genezen.

\section{DE MENSENGENEZER EN DE VLAAMSE LITERATUUR OVER CONGO}

Renders (Koloniseren 145) noemt Ook een ideaal (1896) van Pieter Danco "het eerste Vlaamse fictiewerk over Congo geschreven door een auteur tijdens zijn verblijf aldaar". Tijdens de negentiende en de twintigste eeuw zijn er in de Vlaamse literatuur werken gepubliceerd die direct of indirect over Congo als kolonie gaan, eerst als privé-bezit van Leopold II en dan als kolonie van België. Deze werken behoren tot de koloniale literatuur, tot het genre dat Congo-roman of "Vlaamse literatuur over Congo" genoemd wordt. ${ }^{3}$ Vaak zijn deze werken geschreven in de vorm van reisverslagen, rapporten, romans, verhalen enz. De mensengenezer is niet echt een reisverhaal, maar de auteur gaat wel uit van de traditie van reisverhalen: "In januari 2015 reisde ik naar Kinshasa en Popokabaka, met steun of facilitaire hulp van het Vlaams Fonds voor de Letteren en BRS. Ik kreeg reistips van Lieve Joris, Maarten Couttenier, David Van Reybrouck en Guido Gryseels" (Peeters, De mensengenezer 318). De roman is, zoals gebruikelijk bij reisverslagen, ook voorzien van zestien zwart-wit foto's, maar zonder titels en omschrijvingen.

Luc Renders ("Kolonialistische" 158-165) maakt verschil tussen drie fasen van de literaire productie van Vlaamse auteurs: (1) de periode voor

\footnotetext{
${ }^{3}$ Soms ook Congoroman of Kongoroman geschreven.
} 
1908; (2) de periode van 1908 tot 1960 en (3) de periode na 1960. Deze perioden vallen samen met de belangrijke jaren in de gemeenschappelijke geschiedenis van België en Congo: (1) voor en ten tijde van de CongoVrijstaat (1885-1908); (2) de tijd van Belgisch-Congo (1908-1960) en (3) de tijd na de onafhankelijkheid van Congo in 1960. Renders ( "Kolonialistische" 158) stelt dat de Vlaamse literatuur over Congo vaak onterecht als koloniaal wordt beschouwd, omdat er eveneens auteurs bestaan die een kritische of antikoloniale houding hebbe. Maar er zijn ook auteurs van wie de werken als antikoloniaal worden beschouwd, terwijl dat niet terecht is, zoals, bijvoorbeeld, bij Walschap en Geeraerts (Renders, "Kolonialistische" 158). Renders (Renders, "Kolonialistische" 164-165) concludeert dat de meeste Vlaams-Afrikaanse auteurs, dus Vlamingen die in Congo leven of hebben geleefd, hun werk niet van hun afkomst en culturele erfenis konden scheiden, en daarom alleen hun subjectieve perspectief over Congo beschrijven. Aan de andere kant stellen auteurs als Lieve Joris de vraag of de blanken de zwarten ooit zouden kunnen begrijpen (Renders, "Kolonialistische"165). Waarschijnlijk zou een blanke westerling nooit een andere, niet-blanke en niet-westerse persoon volledig kunnen begrijpen. Toch is er in De mensengenezer een verlangen naar het begrijpen blijkbaar.

Verschillende religieuze denominaties zoals de katholieken en de protestanten waren in Afrika aanwezig tijdens de negentiende en de twintigste eeuw. De Belgische katholieke missionarissen, vooral jezuïeten, hadden een grote invloed op zowel de literatuur als het alledaagse leven. Volgens Luc Renders ("Nikkerke en ikkerke" 304) was zelfs 84 procent van de missionarissen in Congo uit Vlaanderen afkomstig. Volgens Bel ("Congo" 128) stonden de missie en de literatuur van de missie voor belangrijke delen van het koloniaal beleid van Leopold II.

[...] De verhalen werden vaak opgepoetst, ook om geldschieters tevreden te houden die ten slotte heil moesten zien in de onderneming. Missionarissen stonden ook onder strenge controle van de kerkelijke hiërarchie. Van de eigen congregatie, van de kerk, en van de katholieke uitgeverij. [...] (Bel, "Congo" 128)

Meestal waren de missionarissen aanhangers van het koloniale systeem, maar soms waren ze daar kritisch over. Zo is, bijvoorbeeld, in Veertien jaren in den Congo (1904) van Pater Garmijn een "positieve grondhouding" ten aanzien van de inheemse cultuur merkbaar (Bel, "Congo" 128-130). De katholieke Kerk was één van de pijlers van het koloniale regime, samen met het staatsapparaat en het kapitaal (Renders, Koloniseren 100). 
Volgens Bel (Bloed en rozen 825-826) duikt het idee van gelijkheid tussen blank en zwart op in, bijvoorbeeld, Bendsjé of de liefde van een negerin (1931) van E. Tilemans. Toch stelt Pol (67): "Ofschoon Bendsjé dikwijls met respect wordt beschreven als een gevoelsvolle en trouwe vrouw, wordt zij ook meermaals als naiëf en simpel geportretteerd". Ook in De pioniersdagen van Chicongo. Een verhaal uit het pioniersleven in den Congo (1933) van Alfons Vermeulen (1877-1965) wordt de gelijkenis van blank en zwart besproken, wat toch de koloniale houding van het hoofdpersonage niet vermindert (Renders, Koloniseren 351-355).

Van het aantal kolonialistisch-kritische werken valt Bwana Help mij!!! Koloniale folklore (1931) van missionaris J. Esra op. In deze tekst laat de auteur de Congolezen zelf aan het woord, waarbij de "stereotiepe voorstelling van de zwarte in de kolonialistische literatuur" wordt ontkracht (Renders, Koloniseren 358-362). In enkele andere Congo-romans van de twintigste eeuw, zoals bijvoorbeeld in Gangreen I: Black Venus (1968) van Jef Geeraerts (1930-2015) of Ik, blanke kaffer (1970) van Paul Brondeel (1927-2009) zijn de zwarten als inferieur aan de blanken afgebeeld. Peeters gaat door met de observationele benadering die aanwezig is in de werken zoals, bijvoorbeeld, Terug naar Kongo (1987) van Lieve Joris (geb. 1953) en Congo, een geschiedenis (2010) van David Van Reybrouck (geb. 1971). Van de Congo-roman zegt Peeters zelf in De mensengenezer het volgende:

(...) De Congoroman: dat onbenullige genre, met avonturen van paters, jagers en ambtenaren, soms kinderlijk geïllustreerd, vol koloniale daadkracht en de hooggestemde roeping. Ik vond die Congoromans vooral stereotiep en gênant fout: de vet aangezette dromen van jacht en zwarte vrouwen, in een werelddeel waar mensen en dieren nog gelukkig en wild zijn, en ja vandaar de noodzaak van zweep, jachtkarabijn en beschaving. (Peeters, De mensengenezer 102)

Met dit commentaar wil Peeters op wat ironische wijze afstand nemen van de vroegere Congo-romans die volgens hem een negatief beeld van Afrika weergeven. Hij noemt "paters, jagers en ambtenaren" die vaak de hoofdpersonages van de Congo-romans uit de vorige eeuwen zijn. Elk van hen heeft zijn "wapen van keuze": de ambtenaren hun zwepen, de jagers hun jachtkarabijnen en de paters hun beschaving. Deze groepen vertegenwoordigen de Staat, het Kapitaal en de Kerk in de kolonie. Een groot aantal van deze mensen ging naar Afrika onder leiding van het imperialistische idee. De jacht en de zwarte vrouwen zijn de vaak aanwezige motieven in de koloniale literatuur vanwege het feit dat de kolonisatie overwegend een 
onderneming van de blanke man was. De meeste Congo-romans van de twintigste eeuw en eerder bevatten een duidelijk verschil en een verdeling in "de anderen (de zwarten)" en "ons (de blanken)". Met De mensengenezer probeert Peeters tegen de stereotiepe beelden van de vroegere Congo-romans in te gaan. Missionaris Remi beseft dat hij zijn eigen probleem zonder anderen niet zal kunnen oplossen. Om de trauma's uit het verleden te genezen zijn de gezamenlijke inspanningen van beide kanten nodig. De kennis van hoe mensen te genezen interesseert hem meer dan bekeringswerk of andere plichten van de priesters.

\section{CONCLUSIE}

Vanaf het moment dat Remi in de Westhoek het geheime woord van de zwarte soldaat leert, is zijn weg naar Congo op een zekere manier voorbestemd. Net als de missionarissen van de negentiende en twintigste eeuw gaan Remi en zijn student naar Congo en terug, maar zonder "verheven idealen"; ze willen voornamelijk luisteren. Congo vertegenwoordigt in deze roman voor Remi een plaats van psychische genezing, alleen bereikbaar door een gemeenschappelijke ervaring met de Congolezen. In De mensengenezer stelt Peeters het idee voor dat alle mensen bijeengebracht zijn in een "zoektocht naar het donkere in ons", wat een verbindende kracht tussen de mensen vormt.

Het idee van verzoening tussen blank en zwart manifesteert zich in $D e$ mensengenezer vooral in het begrip van communicatie. Het zijn de onzichtbare, onzegbare krachten in ieder mens die tot uiting kunnen komen alleen met behulp van anderen. Het wederzijds luisteren en gesprek is een middel tot genezing. In tegenstelling tot de Oriëntalistische gedachte waar Said over spreekt, wordt in De mensengenezer "de ander" niet op een minachtende wijze bekeken. Eerder heerst er in deze roman een sterk antropologische wijze van denken die een zo objectief mogelijke beschrijving van "de ander" tracht te geven.

\section{BIBLIOGRAFIE}

"Koen Peeters wint de Confituur Boekhandelsprijs 2018". De Bezige Bij. 2018, www. debezigebij. nl/nieuws/koen-peeters-wint-de-confituur-boekhandelsprijs-2018/. Geraadpleegd 16 mei 2020.

Bel, Jacqueline. "Congo, de missie en de literatuur: Over David van Reybrouck, J. G. Schoup en Amaat Vyncke”. Tydskrif vir Letterkunde, vol. 46, nr. 1, 2009, pp. 123-138. 
Bel, Jacqueline. Bloed en rozen. Geschiedenis van de Nederlandse literatuur 1900-1945. Prometheus, 2018.

Brems, Hugo. Altijd weer vogels die nesten beginnen. Geschiedenis van de Nederlandse literatuur 1945-2005. Bert Bakker, 2016.

Brosens, Griet. "Congo aan den Yser: De 32 Congolese soldaten van het Belgisch leger in de Eerste Wereldoorlog". Cahiers Bruxellois - Brusselse Cahiers, vol. 46, 2014, nr. 1N, pp. 253-265.

Buelens, Geert. De jaren zestig: een cultuurgeschiedenis. Ambo Anthos, 2018. Ebook.

Peeters, Koen. De mensengenezer. De Bezige Bij, 2017.

Peters, Arjan. "Koen Peeters wint ECI Literatuurprijs voor De mensengenezer". De Volkskrant 9 november 2017 (recensie), https://www.volkskrant.nl/cultuur-media/koen-peeters-wint-eciliteratuurprijs-voor-de-mensengenezer b $44 \mathrm{c} 6 \mathrm{e} 08 /$ ?referer=https $\% 3 \mathrm{~A} \% 2 \mathrm{~F} \% 2 \mathrm{Fwww}$.google. com\%2F. Geraadpleegd 1 mei 2020.

Pol, Jelmer. Vlaamse paters, bruine schurkentronies en een blanke schijnbeschaving. Een vergelijking tussen litterair proza van Congo en Indië rond 1900 en 1935. Jonge Historici Schrijven Geschiedenis, 2011.

Renders, Luc. "Kolonialistische en anti-kolonialistische tendensen in de Vlaamse Kongo-letterkunde: Het Vlaams-Afrikaanse proza en het kolonialisme". Literatuur, vol. 11, nr. 1, 1994, pp. 158-165.

Renders, Luc. "Nikkerke en ikkerke: Nederlandstalig proza over Kongo." Europa buitengaats. Koloniale en postkoloniale literaturen in Europese talen, onder redactie van Theo d'Haen, Uitgeverij Bert Bakker, 2002, pp. 302-328.

Renders, Luc. Koloniseren om te beschaven. Het Nederlandstalige Congoproza van 1596 tot 1960. Hasselt, Gramadoelas, 2019.

Said, Edward W. Orientalism. Vintage Books, 1979. (Original work published 1978).

Sergier, Matthieu. “Guido's Congo. Koen Peeters' Afrikaanse Westhoek.” Sparks and Lustrous Words, onder redactie van Paul Arblaster, Ingrid Bertrand, Véronique Bragard \& Dirk Delabastita, Presses universitaires de Louvain, 2019, pp. 283-292.

\section{IDEA POJEDNANIA MIĘDZY RASĄ BIAŁĄ I CZARNA \\ W POWIEŚCI DE MENSENGENEZER KOENA PEETERSA}

\section{Streszczenie}

Powieść z motywem Konga („Congo-roman”) stanowi ważny podgatunek literatury flamandzkiej. Już od XVI wieku powstawały niderlandzkojęzyczne teksty o Afryce, a zainteresowanie tym kontynentem rosło w kolejnych stuleciach. W niniejszym artykule omówiono niedawno opublikowaną (2017) powieść z motywem Konga pt. De mensengenezer („Uzdrowiciel ludzi”) współczesnego flamandzkiego pisarza Koena Peetersa (ur. 1959). Artykuł skupia się na relacjach między przedstwicielami rasy białej i czarnej w tej powieści. Większość tego typu powieści z XX wieku i wcześniejszych ukazywała natywnych Afrykańczyków jako gorszych od ludzi białych. Powieść De mensengenezer przedstawia natomiast ideę pojednania między obydwiema rasami.

\section{Przetożyta Beata Poptawska}

Slowa kluczowe: flamandzka literatura o Kongu; Koen Peeters; relacje; kolonializm; postkolonializm. 


\section{THE IDEA OF RECONCILIATION BETWEEN WHITES AND BLACKS IN DE MENSENGENEZER BY KOEN PEETERS}

\section{S u m m a ry}

The "Congo-novel" is an important subgenre in Flemish literature. Dutch texts from as early as the sixteenth century contain passages about Africa. Interest in this continent continued to grow over the following centuries. This article discusses one of the themes present in De Mensengenezer ("The People Healer", 2017), a recently published Congo-novel by the contemporary Flemish author Koen Peeters (born 1959). The focus in this article is on the relationship between whites and blacks in the context of the Congo-novel. Most of the Flemish prose on the Congo from the twentieth century and earlier depicted the blacks as inferior to the whites. Instead, De Mensengenezer offers the idea of reconciliation between these two groups.

Keywords: Flemish Congo-novel; Koen Peeters; relations; colonialism; postcolonialism. 